\title{
Commentary: When suction alone is not enough
}

\footnotetext{
From the Department for Cardiothoracic Surgery, University Hospital Bergmannsheil, Ruhr-University Bochum, Bochum, Germany.

Disclosures: Author has nothing to disclose with regard to commercial support.

Received for publication April 10, 2019; accepted for publication April 10, 2019; available ahead of print May 23, 2019.

Address for reprints: J. F. Matthias Bechtel, MD, Klinik fuer Herz- und Thoraxchirurgie Berufsgenossenschaftliches Universitaetsklinikum Bergmannsheil GmbH, Buerkle-de-la-Camp-Platz 1, 44789 Bochum, Germany (E-mail: matthias.bechtel@bergmannsheil.de).

J Thorac Cardiovasc Surg 2020;159:906-7

$0022-5223 / \$ 36.00$

Copyright (c) 2019 by The American Association for Thoracic Surgery

https://doi.org/10.1016/j.jtcvs.2019.04.047
}

When I learned in whom and how to implant a left ventricular assist device (LVAD), I was taught, among other things, one statement that I still vividly remember. I was told that there is no need to treat mitral insufficiency because "the LVAD will suck the left ventricle empty anyway." More than a decade later, this statement is still covered by guidelines $^{1}$ and current practice. ${ }^{2}$

Recent years, however, have somewhat challenged this attitude. It is clear now that mitral regurgitation does not resolve in all patients. ${ }^{3-5}$ Although most patients with preoperative severe mitral regurgitation seem to fare quite well (or even better than those without preexisting severe mitral regurgitation! ${ }^{6}$ ) postoperatively, there is some evidence that those with persistent moderate to severe mitral regurgitation after LVAD implantation have a poorer prognosis. $^{4,7}$

In this issue of the Journal, Tang and colleagues ${ }^{8}$ try to shed some more light on the effects of severe preoperative mitral regurgitation in patients undergoing LVAD implantation. They identified 159 patients who all had severe mitral regurgitation before implantation of a continuous-flow LVAD. Only 1 patient underwent concomitant mitral valve surgery. Within 1 month of LVAD implantation, an echocardiographic assessment and a right heart catheterization were performed, and the results of these examinations were used for grouping of the patients. Of all patients, $11 \%$ still had severe mitral regurgitation postoperatively; in $27 \%$, postoperative mitral regurgitation was moderate. Separating the entire cohort by the presence of at least moderate mitral regurgitation postoperatively showed worse survival and higher incidence of stroke, hemolysis or pump thrombosis. ${ }^{8}$

Tang and colleagues, ${ }^{8}$ however, went further. By means of cluster analysis, Tang and colleagues, ${ }^{8}$ identified 3 pathways: group 1 had right ventricular dysfunction that did not improve postoperatively but only mild (or less) postoperative mitral and tricuspid regurgitation; group 2 had right ventricular dysfunction that did not improve postoperatively and moderate (or severe) postoperative mitral and

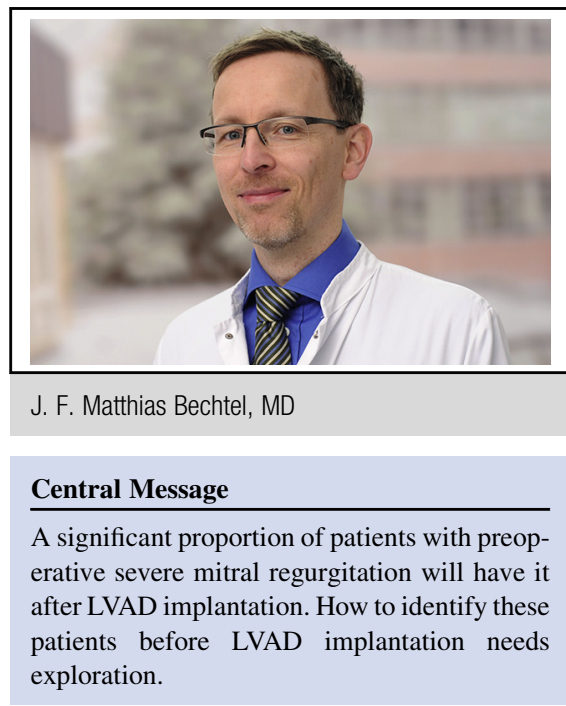

See Article page 897. tricuspid regurgitation; and group 3 had right ventricular dysfunction that did improve postoperatively, still had at least moderate postoperative mitral regurgitation, but had only mild or less postoperative tricuspid regurgitation. Group 1 was the largest $(n=67)$, whereas the other 2 groups were close in size to each other (group 2, $n=43$; group 3 , $n=49$ ). Group 2 had the longest median stays in the intensive care unit and in the hospital and the highest rate of complications; however, this group's 30-day survival and survival to heart transplant were not statistically different from those of the other groups.

The results can be interpreted as follows: A significant proportion of patients with preoperative severe mitral regurgitation will have moderate or severe mitral regurgitation after LVAD implantation. In addition, moderate to severe mitral regurgitation after LVAD implantation or moderate to severe right ventricular dysfunction can be tolerated with quite acceptable outcome. If both are present, however, they affect the prognosis negatively. Tricuspid reconstruction in patients with uncorrected severe mitral regurgitation who undergo LVAD implantation appears to have a negative effect on right heart function.

Unfortunately, the study of Tang and colleagues ${ }^{8}$ does not tell us anything about why mitral regurgitation persists despite the presence of a pump in the left ventricular apex that should be able to unload the ventricle completely. Was there suboptimal placement of the apex cannula? Were the ventricles too small? Are there any factors, such 
as echocardiographic parameters, that predict the persistence of severe mitral regurgitation? ${ }^{9}$

Given that severe mitral regurgitation improves in most patients after LVAD implantation, it might still be prudent generally not to recommend mitral reconstruction for these patients. There appears to be a subgroup of patients, however, who might profit from reestablishment of mitral valve competency. At the moment, it is unclear how to identify these patients before LVAD implantation, and it is also unclear whether they would indeed profit from mitral valve reconstruction. Another strategy might be to wait to see who still has significant mitral valve regurgitation after LVAD implantation and then improve it by percutaneous edge-to-edge repair. ${ }^{10}$

\section{References}

1. Feldmann D, Pamboukian SV, Teuteberg JJ, Birks E, Lietz K, Moore SA, et al; International Society for Heart and Lung Transplantation. The 2013 International Society for Heart Lung Transplantation guidelines for mechanical circulatory support: executive summary. J Heart Lung Transplant. 2013;32:157-87.

2. Robertson JO, Naftel DC, Myers SL, Tedford RJ, Joseph SM, Kirklin JK, et al. Concomitant mitral valve procedures in patients undergoing implantation of continuous-flow left ventricular assist devices: an INTERMACS database analysis. J Heart Lung Transplant. 2018;37:79-88.
3. Morgan JA, Brewer RJ, Nemeh HW, Murthy R, Williams CT, Lanfear DE, et al. Left ventricular reverse remodeling with a continuous flow left ventricular assis device measured by left ventricular end-diastolic dimensions and severity of mitral regurgitation. ASAIO J. 2012;58:574-7.

4. Kassis H, Cheruki K, Agarwal R, Kanwar M, Elapavaluru S, Sokos GG, et al. Significance of residual mitral regurgitation after continuous flow left ventricular assist device implantation. JACC Heart Fail. 2017;5:81-8.

5. Dobrovie M, Spampinato RA, Efimova E, da Rocha E Silva JG, Fischer J, Kuehl M, et al. Reversibility of severe mitral valve regurgitation after left ventricular assist device implantation: single-centre observations from a real-life population of patients. Eur J Cardiothorac Surg. 2018;53:1144-50.

6. Stulak JM, Tchantchaleishvili V, Haglund NA, Schirger JA, Cowger JA, Shah P, et al. Uncorrected pre-operative mitral valve regurgitation is not associated with adverse outcomes after continuous-flow left ventricular assist device implantation. J Heart Lung Transplant. 2015;34:718-23.

7. Tanaka A, Kitahara H, Onsager D, Song T, Raikhelkar J, Kim G, et al. Impact of residual valve disease on survival after implantation of left ventricular assist device. Ann Thorac Surg. 2018;106:1789-96.

8. Tang PC, Haft JW, Romano MA, Bitar A, Hasan R, Palardy M, et al. Right ventricular function and residual mitral regurgitation after left ventricular assist device implantation determines the incidence of right heart failure. $J$ Thorac Cardiovasc Surg. 2020;159:897-905.e4.

9. Kitada S, Kato TS, Thomas SS, Conwell SD, Russo C, Di Tullio MR, et al. Preoperative echocardiographic features associated with persistent mitral regurgitation after left ventricular assist device implantation. J Heart Lung Transplant. 2013;32:897-904.

10. Cork DP, Adamson R, Gollapudi R, Dembitsky W, Jaski B. Percutaneous repair of postoperative mitral regurgitation after left ventricular assist device implant. Ann Thorac Surg. 2018;105:e45-6. 